\title{
Utilization of intermittent preventive treatment for malaria among pregnant women attending antenatal clinics in health facilities of Cross River State, Nigeria
}

\author{
Ekpereonne Esu' ${ }^{1,2}$ \\ Emmanuel Effa ${ }^{1,2}$ \\ Ekong Udoh ${ }^{1,2}$ \\ Olabisi Oduwole ${ }^{1,2}$ \\ Friday Odey ${ }^{1,2}$ \\ Moriam Chibuzor ${ }^{1}$ \\ Angela Oyo-Ita ${ }^{1,2}$ \\ Martin Meremikwu ${ }^{1,2}$ \\ 'Calabar Institute of Tropical Diseases \\ Research and Prevention, University \\ of Calabar Teaching Hospital, Calabar, \\ Nigeria; ${ }^{2}$ College of Medical Sciences, \\ University of Calabar, Calabar, Nigeria
}

Correspondence: Martin Meremikwu Department of Pediatrics, University of Calabar, PO Box 3134, GPO, Calabar, Nigeria

Tel +2348036742377

Email mmeremiku@yahoo.co.uk

\author{
This article was published in the following Dove Press journal: \\ Research and Reports in Tropical Medicine \\ 19 September 2013 \\ Number of times this article has been viewed
}

Objective: This study assessed the utilization of intermittent preventive treatment with sulfadoxine-pyrimethamine for the prevention of malaria in pregnancy against the national treatment policy among women attending health care facilities in Cross River State, Nigeria.

Methods: A clinical audit was carried out between January 2012 and March 2012 using case records of pregnant women who received antenatal care in health facilities in the state. Facilities were selected by simple random sampling. Information on the frequency of antenatal clinic (ANC) visits by the women, as well as parity, age, and adherence to intermittent preventive treatment (IPTp) doses was obtained using an audit checklist.

Results: A total of 322 pregnant women were assessed across 36 health care facilities. In addition, 246 (76\%) of them attended the ANC in public health facilities. Age, parity, and gestational age at booking were recorded in more than $95 \%$ of the cases evaluated. The audit showed that $13.7 \%$ of the women did not utilize IPTp, 53.1\% had one dose of IPTp (IPTp1), 24.2\% had two doses of IPTp (IPTp2), while 3.1\% had three doses of IPTp (IPTp3). The overall utilization of two doses or more of IPTp (IPTp2+) was 30.7\%.

Conclusion: There was good documentation of the basic obstetric information of pregnant women in the health care facilities examined in this study, but the overall utilization of IPTp was very low. Efforts at ensuring early ANC booking and regular visits may be a potential means of increasing IPTp utilization in health care facilities in the state.

Keywords: intermittent preventive treatment, malaria, pregnancy, clinical audit, resourcelimited setting

\section{Introduction}

Globally, there are about 216 million cases of malaria annually, with an estimated 650,000 deaths. ${ }^{1}$ Sub-Saharan African populations living in highly endemic areas account for a majority of the global malaria burden, with pregnant women and infants being at a disproportionately higher risk of infection than others. ${ }^{2}$ It is estimated that 75,000-200,000 infant deaths occur yearly in Africa from malaria in pregnancy. ${ }^{3}$ In Nigeria, malaria accounts for about $11 \%$ of maternal deaths. ${ }^{4}$

Women of reproductive age residing in malaria-endemic areas acquire partial immunity to the malaria parasite, which is modulated during pregnancy. ${ }^{5}$ Plasmodium falciparum parasitization of the red blood cells in placental circulation with or without peripheral parasitemia, is known to have a deleterious effect on pregnancy. ${ }^{6}$ The complications of malaria during pregnancy include maternal anemia, fetal anemia, stillbirth, 
premature delivery, low birth weight, as well as increased risk of perinatal and neonatal morbidity and mortality. ${ }^{7-11}$

The World Health Organization (WHO), in response to the high burden and adverse effect of malaria in pregnancy among women residing in high-transmission areas, recommended intermittent treatment with sulfadoxine-pyrimethamine (SP-IPTp) as a strategy for preventing malaria in pregnancy. ${ }^{12}$ SP-IPTp consists of supervised treatment with a curative dose of SP in the second and third trimesters of pregnancy during routinely scheduled antenatal clinic (ANC) visits, regardless of whether the woman is infected or not. ${ }^{13}$ The national guideline on IPTp recommends that the first dose be given at a gestational age (GA) of $\geq 18$ weeks with the subsequent doses given at least 4 weeks from each other. ${ }^{4}$

Evidence from a systematic review and clinical trials had shown SP-IPTp to be effective in reducing the risk of pregnancy-related malaria morbidities in endemic regions. ${ }^{14,15}$ The incidence of maternal anemia, peripheral parasitemia, placental parasitemia, and low birth weight were much lower in women that received SP-IPTp when compared with those that did not. ${ }^{14,15}$

The WHO has recently increased its desired target of IPTp coverage from $80 \%-100 \% .{ }^{16}$ Achieving this new target at a country or regional level will go a long way in enhancing maternal and newborn survival. The intervention is to be offered to all ANC attendees in every health facility as part of their antenatal care services.

The national coverage for SP-IPTp in Nigeria reported in 2011 was $18.7 \%$, which implied that over $80 \%$ of pregnant women in the country were at risk of malaria-related adverse events. ${ }^{17}$ Various states of the country have since intensified efforts at achieving the maternal Millennium Development Goal (MDG)-related targets. As 2015 - the year set by the WHO for the attainment of MDG targets - draws near, it is necessary to monitor the progress and evaluate the quality of current practices in preventing malaria during pregnancy in the country. The aim of this study was to assess the utilization of SP-IPTp according to the national guidelines for preventing malaria in pregnancy among women attending health care facilities in Cross River State, Nigeria.

\section{Methods}

\section{Study design and settings}

The study was conducted in 36 primary and secondary health care facilities situated in rural and urban areas of Cross River State, Nigeria between January 2012 and March 2012. The study area is located within the tropical rain forest belt of southern Nigeria, and has an annual rainfall of $2,500 \mathrm{~mm}$ to
3,500 $\mathrm{mm}$. The population of Cross River State was estimated to be 2.389 million persons in 2006 , of which $50.03 \%$ were males $(1,195,520)$ and $49.97 \%$ were females $(1,194,293)$. The population of the state as of December 2010 was projected to be $3,251,557$. The Cross River State Ministry of Health coordinates health care delivery to the public in the state through 548 primary health care facilities, and 17 secondary health care facilities across 18 local government areas (LGAs). The Ministry also regulates health care practice by private providers in Cross River State. Malaria transmission is intense and perennial in this area. ${ }^{18}$

\section{Sampling methods}

Multistaged sampling was used to select the facilities to be audited. Cross River State comprises three senatorial districts each made up of five to seven LGAs. Four LGAs (two from the south district, one each from the north and central districts) were selected by simple random sampling. Primary (public) and secondary (public and private) health care facilities were then selected by simple random sampling. The sampling frame was a list of all the registered health care facilities in the four selected LGAs obtained from the Cross River State Ministry of Health. The total number of facilities in these selected LGAs was 189. Sixty-six were privatelyowned secondary facilities, while 123 were public facilities (119 primary and four secondary) health facilities. At the LGA level, the health facilities were stratified into public (ie, government-owned) and privately owned facilities. There was only one general hospital/specialist hospital in each of the sampled LGAs and they were audited. Twenty primary (public) health facilities (five per LGA) were also audited. The private hospitals and clinics were randomly selected (four per LGA) from the list of registered facilities obtained from the health ministry.

Thus, data was collected from 24 public health facilities (four general/specialist hospitals and 20 primary health facilities), and twelve out of about 40 functional private hospitals and clinics. Outside the state capital, in the selected LGAs, there were fewer functional private hospitals and clinics found than on the registered list obtained from the health ministry. Moreover, many of them did not have ANCs.

\section{Data collection}

In each facility, the last ten case records of pregnant women who attended antenatal care in the selected facilities and who delivered within 6 months prior to the study were assessed. Medical doctors, nurses, community health officers, and laboratory scientists were trained on the study procedure, and 
worked concurrently to extract data from patient records in the selected health facilities using pretested data extraction forms. Data obtained included patients' bio demographic data, details about intermittent preventive treatment, and the GA at which treatment was received.

\section{Data management and analysis}

Results from all LGAs were combined and descriptive analysis was performed based on ownership of the health care facilities (publicly- or privately-owned). Data entry and analysis were done with Microsoft Excel 2007 (Microsoft Corporation, Redmond, WA, USA) and Stata ${ }^{\circledR}$ (StataCorp LP, College Station, TX, USA), respectively, and results were presented as proportions and frequencies. Chi-square was used to test the relationships between categorical variables. A $P$-value less than 0.05 was considered statistically significant.

\section{Ethical considerations and approval}

The Cross River State Health Research Ethics Committee reviewed and approved the study. Consent was obtained from the management of the selected health care facilities prior to the audit. The confidentiality of the patients' records and clinicians' identities were adequately protected.

\section{Results}

\section{General patient information}

A total of 322 case records of pregnant women who registered for antenatal care in 36 health facilities (24 primary and twelve secondary) and who delivered 6 months prior to the clinical audit were assessed. Of this number, 240 (76\%) received antenatal care in publicly-owned health facilities

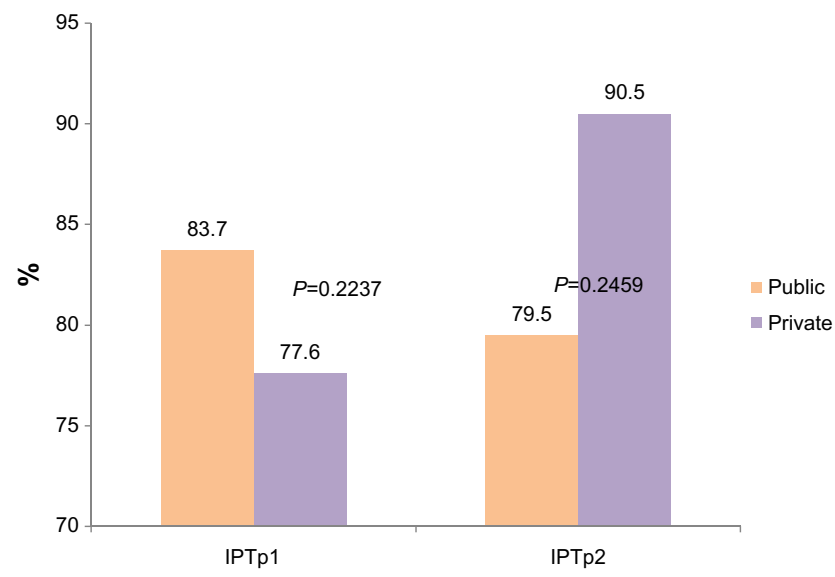

Figure I Percentage of the correct timing of IPTPI and IPTP2 doses among pregnant women attending ANCs.

Abbreviations: IPTPI, one dose of intermittent preventive treatment; IPTp2, two doses of intermittent preventive treatment; ANCs, antenatal clinics. with the remainder in privately-owned health facilities. The date of booking was recorded for all cases audited. Generally, age, parity, and GA at booking were recorded in at least $95 \%$ of the cases assessed (Table 1).

\section{Utilization of ANC and IPTP}

Of the 322 case records of pregnant women audited, $103(32 \%)$ had one ANC visit, 90 (28.0\%) had two visits, while $52(16.1 \%)$ had three visits (Table 2). This audit shows that $50(15.5 \%)$ women did not receive SP, $173(53.7 \%)$ received one dose of SP (IPTp1), 88 (27.3\%) received two doses of SP (IPTp2). while ten (3.1\%) received three doses of SP. The percentage of women who received two or more doses of SP (IPTp2+) was 30.7\% (99), as shown in Table 2.

Table 3 shows the proportion of pregnant women who received two doses of SP at the correct GA wherein the first dose was given at a GA of $\geq 18$ weeks, and the second dose was given at least 4 weeks from the first. It is observed that the utilization of IPTp1 was correct in $83.7 \%$ of cases in the public health facilities as compared to $77.6 \%$ of cases in privately-owned health facilities. Correct utilization of IPTp 2 was recorded in $80 \%$ of women that attended public facilities, as compared to $91 \%$ that attended privately-owned facilities.

Table 4 shows the doses of IPT received according to the GA at booking. This result shows that $61.2 \%$ of the women booked in the second trimester, while $28.8 \%$ booked in the third trimester. Among those that booked in the first or third trimesters, $22.5 \%$ did not receive IPTp, about $57.0 \%$ received one dose, while $19.0 \%$ received two doses; conversely, of those that booked in the second trimester, $11.6 \%$ did not receive IPTp, 51.3\% received one dose, and 32.3\% received two doses. The relationship between IPTp received and GA at booking was statistically significant $\left(\chi^{2}=12.81\right.$; degrees of freedom $[d f]=6 ; P=0.0462$ ).

Table I Patients' general information

\begin{tabular}{llll}
\hline Variables & $\begin{array}{c}\text { Public } \\
(\mathbf{n}=\mathbf{2 4})\end{array}$ & $\begin{array}{l}\text { Private } \\
(\mathbf{n}=\mathbf{1 2})\end{array}$ & Total \\
\hline $\begin{array}{l}\text { Ownership of health facility } \\
\text { Number of cases audited }\end{array}$ & 246 & 76 & $322(100 \%)$ \\
$\begin{array}{l}\text { Date of booking recorded } \\
\text { Age recorded } \\
\quad 246\end{array}$ & 76 & $322(100 \%)$ \\
$\begin{array}{l}\text { Yestational age at booking } \\
\text { recorded }\end{array}$ & 245 & 76 & $321(99.7 \%)$ \\
$\quad$ Yes & 240 & 69 & $309(95.7 \%)$ \\
$\begin{array}{l}\text { Parity recorded } \\
\text { Yes }\end{array}$ & 235 & 71 & $306(95.0 \%)$ \\
\hline
\end{tabular}

Abbreviation: $n$, number. 
Table 2 Antenatal care visits and utilization of IPTp for malaria in pregnancy

\begin{tabular}{llll}
\hline Variables & $\begin{array}{l}\text { Public } \\
(\mathbf{n}=\mathbf{2 4})\end{array}$ & $\begin{array}{l}\text { Private } \\
(\mathbf{n}=\mathbf{1 2})\end{array}$ & Total \\
\hline $\begin{array}{l}\text { Ownership of health facility } \\
\text { Number of cases audited }\end{array}$ & $246(76.4)$ & $76(23.6)$ & $322(100 \%)$ \\
$\begin{array}{l}\text { Frequency of ANC visits } \\
\text { I }\end{array}$ & 82 & 21 & $103(32.0 \%)$ \\
2 & 69 & 21 & $90(28.0 \%)$ \\
3 & 39 & 13 & $52(16.1 \%)$ \\
$\geq 4$ & 56 & 21 & $77(23.9 \%)$ \\
Number of IPTP doses & & & \\
0 & 38 & 12 & $50(15.5 \%)$ \\
I & 130 & 43 & $173(53.7 \%)$ \\
2 & 69 & 19 & $88(27.3 \%)$ \\
3 & 8 & 2 & $10(3.1 \%)$ \\
4 & 1 & 0 & $1(0.3 \%)$ \\
\hline
\end{tabular}

Abbreviations: $n$, number; ANC, antenatal clinic; IPTp, intermittent preventive treatment.

Table 5 shows a statistically significant difference in the doses of IPT received by women that booked in the second trimester when compared to those that booked in the third trimester $\left(\chi^{2}=9.679 ; d f=3 ; P=0.0215\right)$, while Table 6 shows a significant difference in the doses of IPT received between women that had the first dose in the second trimester when compared to those that had it in the third trimester $\left(\chi^{2}=7.124 ; d f=2 ; P=0.0284\right)$.

\section{Discussion}

The findings of this audit show that essential obstetric information was obtained from most of the women that received antenatal care services in the health facilities in the state during the period of the review. This essential information, if properly utilized, will enable health care providers to adopt an individualized approach in the management of pregnant women who present to the facilities.

Table 3 Correct timing of the first two IPTp doses according to facility type

\begin{tabular}{llll}
\hline \multicolumn{1}{c}{$\begin{array}{l}\text { Public } \\
\mathbf{n}(\%)\end{array}$} & $\begin{array}{l}\text { Private } \\
\mathbf{n}(\%)\end{array}$ & Total \\
\hline $\begin{array}{l}\text { IPTp dose given at the correct time? } \\
\text { First dose } \\
\text { Yes } \\
\text { No }\end{array}$ 206(83.7) & $59(77.6)$ & $265(82.3)$ \\
Unclear & $11(4.5)$ & $17(22.4)$ & $28(8.7)$ \\
Second dose & $29(11.8)$ & - & $29(9)$ \\
Yes & $62(79.5)$ & $19(90.5)$ & $81(81.8)$ \\
No & $6(7.7)$ & - & $6(6.1)$ \\
Unclear & $10(12.8)$ & $2(9.5)$ & $12(12.1)$ \\
\hline
\end{tabular}

Abbreviations: IPT, intermittent preventive treatment; $n$, number.
The recent introduction of focused antenatal care by the WHO stems from the need to identify and provide adequate care to pregnant women that might have medical, surgical, or obstetric problems on an individualized basis. ${ }^{19}$ Malaria in pregnancy, with or without anemia as a complication, is a major medical problem that contributes significantly to maternal morbidity and mortality in endemic regions. ${ }^{3}$ A good record of the basic obstetric information such as age, parity, and GA at booking, as observed in this audit, could go a long way in identifying women at high risk of poor outcomes from malaria in pregnancy.

The number of ANC visits by pregnant women was generally low. The highest number was recorded in one-third of the women who visited the facilities only on the day they registered for ANC. There was a progressive decline in the frequency of subsequent visits in the others, with less than a quarter meeting the four target $\mathrm{ANC}$ visits throughout pregnancy, as currently recommended by the WHO. ${ }^{20}$ The pattern of ANC visits in this study is very similar to what has been reported in other studies in the country and in the subregion. $^{21,22}$ This low turnout for ANC visits by pregnant women implies that the majority of pregnant women that registered in health care facilities in the state do not get the full benefit of ANC services; they probably deliver their babies in nonformal health facilities and are therefore at high risk of negative pregnancy outcomes.

The overall utilization of IPTp2+ in this audit was 30.7\%. This is far below the desired $100 \%$ IPTp2+ coverage recommended by the WHO. ${ }^{1}$ Even though about half of the women in the study had a dose of IPTp, the intervention is considered effective only when women receive at least two correct doses according to the National Malaria Treatment Policy. ${ }^{4}$

The low uptake of IPT in this study can be partly explained by the low ANC attendance rate already stated. This trend is consistent with reports from other parts of Nigeria. ${ }^{23}$

Besides the low frequency of ANC attendance by pregnant women, late registration for ANC services was another factor that influenced the low utilization of IPT in the health facilities. About a one-third of the women in this audit booked in the third trimester, which was rather late. The women in this category were less likely to receive IPTp and IPTp2+ when compared to those that booked in the second trimester. A quarter of the women that had only one dose of SP-IPTp booked for ANC in the third trimester and were not eligible for the second dose, based on their estimated delivery date. The association between IPTp utilization and the trimester at booking or the trimester of administration of the first dose of 
Table 4 Number of IPTp doses received by study women according to gestational age at booking

\begin{tabular}{|c|c|c|c|c|c|c|c|}
\hline & \multicolumn{4}{|c|}{ Number of IPTp doses } & \multirow[t]{2}{*}{ Total } & \multirow[t]{2}{*}{ Test statistic } & \multirow[t]{2}{*}{$P$-value } \\
\hline & 0 & $\mathbf{I}$ & 2 & $\geq 3$ & & & \\
\hline \multicolumn{8}{|c|}{ Gestational age at booking } \\
\hline $\begin{array}{l}\text { Ist trimester } \\
(0-13 \text { weeks }) \\
n=3 \mid(10 \%)\end{array}$ & $7(22.5 \%)$ & I 8 (58.1\%) & $6(19.2 \%)$ & - & $31(100 \%)$ & $\begin{array}{l}\chi^{2}=12.81 \\
d f=6\end{array}$ & \\
\hline $\begin{array}{l}\text { 2nd trimester } \\
(14-26 \text { weeks) } \\
n=189(61.2 \%)\end{array}$ & $22(11.6 \%)$ & 97 (5।.3\%) & $61(32.3 \%)$ & $9(4.8 \%)$ & $189(100 \%)$ & & 0.0462 \\
\hline $\begin{array}{l}3 r d \text { trimester } \\
(\geq 27 \text { weeks }) \\
n=89(28.8 \%)\end{array}$ & 20 (22.5\%) & $50(56.2 \%)$ & 17 (19.1\%) & $2(2.2 \%)$ & $89(100 \%)$ & & \\
\hline
\end{tabular}

Note: A total of I 3 women were not included in analyses because the gestational age at booking was not recorded.

Abbreviations: IPTp, intermittent preventive treatment; $n$, number; $\mathrm{df}$, degrees of freedom.

IPT is statistically significant. Booking at the second trimester significantly increased the chance of IPT utilization when compared to the third. Late presentation of pregnant women at health facilities for ANC can compromise the benefit of ANC services, as these women may no longer be eligible for such services. ${ }^{24}$

It is worthy to note that the pattern of IPT uptake among women that booked in the first trimester was quite similar to those that booked in the third trimester. Women that booked in the first trimester were expected to have a higher IPT uptake which, however, was not the case. This may be explained by the fact that IPT is not usually administered in the first trimester and that some of these women probably defaulted in their ANC visits after the initial booking.

The second trimester of pregnancy appears to be the critical period for optimization of IPT uptake, as shown by the significant increase in ANC bookings and time of administration of the first dose of IPT, especially when compared to first trimester or third trimester bookings. This is further highlighted by the fact that there was no significant difference in the uptake between early bookings (first trimester and second trimester bookings) when compared with late bookings (third trimester bookings). However, since IPT is not the only service offered to pregnant women during the antenatal period, early ANC booking still needs to be emphasized.

To improve the utilization of IPTp, effort needs to be made at getting pregnant women to book early enough for ANC in the health facilities and to help them keep their scheduled ANC visits. Regular ANC attendance could lead to the prevention, identification, and early treatment of maternal illnesses and obstetric complications. ${ }^{20}$ A study in Tanzania, however, did not show a proportionate increase in IPTp utilization with increased ANC visits, suggesting that the frequency of ANC visits is not the only determinant of IPTp uptake in a community. This highlights the need to explore other variables like sociocultural, economic, political, and individual perceptions regarding IPTp in a contextual perspective. ${ }^{25}$

Tracking progress in relation to attainment of maternal-related MDG with respect to IPTp may be a bit difficult because the framework for effective monitoring and

Table 5 Number of IPTp doses received by study women according to gestational age at booking, comparing only second and third trimester antenatal bookings

\begin{tabular}{|c|c|c|c|c|c|c|}
\hline & \multicolumn{4}{|c|}{ Number of IPTp doses } & \multirow[t]{2}{*}{ Test statistic } & \multirow[t]{2}{*}{$P$-value } \\
\hline & 0 & $\mathbf{I}$ & 2 & $\geq 3$ & & \\
\hline \multicolumn{7}{|c|}{ Gestational age at booking } \\
\hline $\begin{array}{l}\text { 2nd trimester } \\
\mathrm{n}=189 \\
(14-26 \text { weeks) }\end{array}$ & $22(52.4)$ & $97(66)$ & $61(78.2)$ & $9(81.8)$ & & \\
\hline $\begin{array}{l}\text { 3rd trimester } \\
\mathrm{n}=89 \\
(\geq 27 \text { weeks })\end{array}$ & $20(47.6)$ & $50(34)$ & $17(2 \mid .8)$ & $2(19.2)$ & $\begin{array}{l}\chi^{2}=9.679 \\
d f=3\end{array}$ & \\
\hline Total & $42(100)$ & $147(100)$ & $78(100)$ & II (I00) & & 0.0215 \\
\hline
\end{tabular}

Abbreviations: IPTp, intermittent preventive treatment; n, number; df, degrees of freedom. 
Table 6 Number of IPTp intermittent preventive treatment doses received by study women according to gestational age at first dose

\begin{tabular}{|c|c|c|c|c|c|}
\hline & \multicolumn{3}{|c|}{ Number of IPTp doses } & \multirow[t]{2}{*}{ Test statistic } & \multirow[t]{2}{*}{$P$-value } \\
\hline & $\mathbf{I}$ & 2 & $\geq 3$ & & \\
\hline \multicolumn{6}{|c|}{ Gestational age at booking } \\
\hline $\begin{array}{l}\text { 2nd trimester } \\
n=177 \\
(14-26 \text { weeks) }\end{array}$ & $102(6 \mid .4)$ & $66(76.7)$ & $9(81.8)$ & & \\
\hline $\begin{array}{l}\text { 3rd trimester } \\
\mathrm{n}=86 \\
(\geq 27 \text { weeks })\end{array}$ & $64(38.6)$ & $20(23.3)$ & $2(18.2)$ & $\begin{array}{l}\chi^{2}=7.124 \\
d f=2\end{array}$ & \\
\hline Total & $166(100)$ & $86(100)$ & II (I00) & & 0.0284 \\
\hline
\end{tabular}

Abbreviations: IPTp, intermittent preventive treatment; $n$, number; df, degrees of freedom.

evaluation is not in place in most parts of the country. The national guidelines and strategies for malaria prevention and control states that IPTp should be administered in health facilities under the direct supervision of the health care providers, the guidelines are silent on the means of procurement of the commodity. ${ }^{4}$

In a country where most people are living below the poverty line, cost is an important consideration in the uptake of health care services. Since malaria is a major contributor to the unacceptably high maternal and infant mortality rates, the government should work out a mechanism that will ensure that SP-IPTp is made available at no cost to all pregnant women in the country. This measure may encourage women to receive the drug, thus ensuring accurate data on SP-IPTp utilization in the facilities, and forming the basis for utilization of other ANC services. It could also encourage the women to deliver their babies in facilities and increase the public's overall confidence levels in the country's health care system.

The IPTp2 utilization of $27.4 \%$ reported in health facilities in the state is very low when compared with the $100 \%$ desired national coverage. Since the reported coverage observed in this study was among pregnant women who booked at ANCs, the overall coverage for the state that is inclusive of pregnant women who were not booked at ANCs may lie between the 2010 and 2011 national averages of $13.2 \%$ and $18.7 \%$, respectively, though these rates could be even lower. Based on the rate of IPT utilization among booked pregnant women in this study, the country is unlikely to attain the malaria-related MDGs by 2015. Since performance at the country level is a reflection of performance at the local and state government levels, it is therefore necessary to intensify efforts at scaling up SPIPTp utilization at these levels to meet the desired target by 2015 .

\section{Conclusion}

There is adequate documentation of basic obstetric information of pregnant women attending ANCs in health facilities in Cross River State, Nigeria, but the utilization of IPTp among booked pregnant women in the facilities is very low. Strategies at encouraging early ANC booking and regular ANC visits will go a long way in improving IPT utilization in the health facilities.

\section{Acknowledgments}

M Meremikwu conceived the study; F Odey, E Esu, E Effa, A Oyo-Ita, O Oduwole and E Udoh participated in the research design and supervised data collection from the field; and E Esu supervised the data analysis. E Esu and E Udoh contributed to data interpretation and writing of the draft. M Meremikwu was the overall supervisor of the project and revised the draft extensively. M Chibuzor participated in the research design and supervised data collection from the field. All authors contributed to the drafting, critical revising of the manuscript and approved the final manuscript.

The authors appreciate the support and cooperation of the local government authorities and proprietors in the selected publicly-owned health facilities and privately-owned clinics, respectively. We also acknowledge the contributions of the nurses, records personnel, and interviewers who aided in the data collection process.

\section{Disclosure}

The authors report no conflicts of interest in this work.

\section{References}

1. World Health Organization. World Malaria Report 2011. Geneva, Switzerland: World Health Organization; 2011. 
2. Heggenhougen HK, Hackethal V, Vivek P. The Behavioral and Social Aspects of Malaria and its Control: An Introduction and Annotated Bibliography. Geneva, Switzerland: UNDP, World Bank, WHO Special Programme for Research and Training in Tropical Disease (TDR); 2003.

3. Steketee RW, Nahlen BL, Parise ME, Menendez C. The burden of malaria in pregnancy in malaria-endemic areas. Am J Trop Med Hyg. 2001;64(Suppl 1-2):28-35.

4. Federal Ministry of Health. National Guidelines and Strategies for Malaria Prevention and Control during Pregnancy. Abjuba, Nigeria: Federal Ministry of Health Abuja Nigeria; 2004.

5. Fievet N, Cot M, Chougnet C, et al. Malaria and pregnancy in Cameroonian primigravidae: humoral and cellular immune responses to Plasmodium falciparum blood-stage antigens. Am J Trop Med Hyg 1995;53(6):612-617.

6. Samak AC. Malaria in pregnancy: an overview. McGill J Med. 2004;8: 66-71.

7. Brabin BJ. The Risks and Severity of Malaria in Pregnant Women. Geneva, Switzerland: World Health Organization; 1991.

8. Menendez C. Malaria during pregnancy: a priority area of malaria research and control. Parasitol Today. 1995;11(5):178-183.

9. Schellenberg D, Schellenberg JR, Mushi A, et al. The silent burden of anaemia in Tanzanian children: a community-based study. Bull World Health Organ. 2003;81(8):581-590.

10. Marchant T, Schellenberg JA, Nathan R, et al. Anaemia in pregnancy and infant mortality in Tanzania. Trop Med Int Health. 2004;9(2): 262-266.

11. Rogawski ET, Chaluluka E, Molyneux ME, Feng G, Rogerson SJ, Meshnick SR. The effects of malaria and intermittent preventive treatment during pregnancy on fetal anemia in Malawi. Clin Infect Dis. 2012;55(8):1096-1102.

12. World Health Organization. A Strategic Framework for Malaria Prevention and Control During Pregnancy in the African Region. Brazzaville, Republic of the Congo: World Health Organization Regional Office for Africa; 2004.

13. Falade CO, Yusuf BO, Fadero FF, Mokuolu OA, Hamer DH, Salako LA. Intermittent preventive treatment with sulphadoxine-pyrimethamine is effective in preventing maternal and placental malaria in Ibadan, southwestern Nigeria. Malar J. 2007;6:88.

14. Gamble C, Ekwaru JP, ter Kuile FO. Insecticide-treated nets for preventing malaria in pregnancy. Cochrane Database Syst Rev. 2006: CD003755.
15. Garner P, Gülmezoglu AM. Drugs for preventing malaria in pregnant women. Cochrane Database Syst Rev. 2006:CD000169.

16. Wilson NO, Ceesay FK, Obed SA, et al. Intermittent preventive treatment with sulfadoxine-pyrimethamine against malaria and anemia in pregnant women. Am J Trop Med Hyg. 2011;85(1):12-21.

17. Roll Back Malaria. Refined/Updated GMAP Objectives, Targets, Milestones and Priorities Beyond 2011. Geneva, Switzerland: World Health Organization; 2011.

18. National Population Commission, Nigeria. 2010 Malaria Indicator Survey (MIS). Abuja, Nigeria: National Population Commission; 2010.

19. Amosu AM, Degun AM, Thomas AM, et al. A study on the acceptance and practice of focused antenatal care by healthcare providers in the south-west zone of Nigeria. Archives of Applied Science Research. 2011;3(1):484-491.

20. Bouyou-Akotet MK, Mawili-Mboumba DP, Kombila M. Antenatal care visit attendance, intermittent preventive treatment and bed net use during pregnancy in Gabon. BMC Pregnancy Childbirth. 2013;13:52.

21. Onoka CA, Hanson K, Onwujekwe OE. Low coverage of intermittent preventive treatment for malaria in pregnancy in Nigeria: demand-side influences. Malar J. 2012;11:82.

22. Ndyomugyenyi R, Katamanywa J. Intermittent preventive treatment of malaria in pregnancy (IPTp): do frequent antenatal care visits ensure access and compliance to IPTp in Ugandan rural communities? Trans R Soc Trop Med Hyg. 2010;104(8):536-540.

23. Akinleye SO, Falade CO, Ajayi IO. Knowledge and utilization of intermittent preventive treatment for malaria among pregnant women attending antenatal clinics in primary health care centers in rural southwest, Nigeria: a cross-sectional study. BMC Pregnancy Childbirth. 2009;9:28.

24. Guyatt HL, Noor AM, Ochola SA, Snow RW. Use of intermittent presumptive treatment and insecticide treated bed nets by pregnant women in four Kenyan districts. Trop Med Int Health. 2004;9(2):255-261.

25. Anders K, Marchant T, Chambo P, Mapunda P, Reyburn H. Timing of intermittent preventive treatment for malaria during pregnancy and the implications of current policy on early uptake in north-east Tanzania Malar J. 2008;7:79.
Research and Reports in Tropical Medicine

\section{Publish your work in this journal}

Research and Reports in Tropical Medicine is an international, peerreviewed, open access journal publishing original research, case reports, editorials, reviews and commentaries on all areas of tropical medicine, including: Diseases and medicine in tropical regions; Entomology; Epidemiology; Health economics issues; Infectious disease; Laboratory

\section{Dovepress}

science and new technology in tropical medicine; Parasitology; Public health medicine/health care policy in tropical regions; and Microbiology. The manuscript management system is completely online and includes a very quick and fair peer-review system. Visit http://www.dovepress. com/testimonials.php to read real quotes from published authors. 